\title{
Utilization, Barriers and Determinants of Emergency Medical Services in Mekelle City, Tigray, Ethiopia: A Community-Based Cross-Sectional Study
}

\author{
Goitom Molalign Takele $\mathbb{D}^{\prime}$ \\ Tsegalem Hailemariam Ballo' \\ Kiros Belay Gebrekidan ${ }^{2}$ \\ Birhan Gebresillassie \\ Gebregiorgis $\mathbb{1}^{3}$ \\ 'Department of Emergency and Critical \\ Care Nursing, School of Nursing, College \\ of Health Sciences, Mekelle University, \\ Mekelle, Ethiopia; ${ }^{2}$ Department of Adult \\ Health Nursing, School of Nursing, \\ College of Health Sciences, Mekelle \\ University, Mekelle, Ethiopia; \\ ${ }^{3}$ Department of Nursing, College of \\ Health Sciences, Debre Berhan \\ University, Debre Berhan, Ethiopia
}

Background: Emergency medical services (EMS) are services that provide out-of-hospital emergency medical care to injured or ill peoples, and transporting to definitive care. EMS is an integral part of the emergency medical system and has been associated with decreased morbidity and mortality related to emergency cases. The aim of this study was to assess the utilization, barriers, and determinants of EMS in Mekelle, Ethiopia.

Methods: A community-based cross-sectional study was conducted in selected sub-cities of Mekelle. A multistage sampling method was employed to recruit study participants, and data were collected by trained data collectors using an interviewer-administered questionnaire. Multivariate logistic regression analysis was used to examine the statistical association of the determinants of EMS utilization.

Results: Half $(50.5 \%)$ of the respondents had experienced or witnessed an emergency incident in the past year. The common means of transportations used were Bajaj's (39.2\%) and ambulances $(22.7 \%)$. Majority $(88.1 \%)$ of the respondents did not knew the EMS access phone number of an ambulance. As their preferred mode of transportation in case of emergency conditions, $42.2 \%$ of the participants reported an ambulance, followed by Bajaj 33.7\%. Where participants who had gynecologic emergencies were 9.4 times $(\mathrm{AOR}=9.4,95 \% \mathrm{CI}: 1.04,85$, $\mathrm{p}=0.046$ ), and those who knew any ambulance numbers were 3.6 times ( $\mathrm{AOR}=3.6,95 \% \mathrm{CI}: 1.22$, $10.8, \mathrm{p}=0.02$ ) more likely to use ambulance services in case of emergencies.

Conclusion: The ambulance utilization level in Mekelle city was low and victims of emergency conditions were being transported mainly using public transports such as Bajaj's and taxis. Even though the perception of the public towards EMS services is favorable, lack of awareness of EMS access, and lack of integrated EMS system in the city are the barriers that may have contributed to the low utilization. Actions to improve EMS access and integrating the system are warranted to promote the services utilization.

Keywords: barriers, emergency medical services, utilization, Mekelle

\section{Introduction}

Emergency medical services (EMS) also known as ambulance services or paramedic services are emergency services that treat illnesses and injuries that require an urgent medical response, providing out-of-hospital treatment, and transport to the definitive care. $^{1}$ Where effectively implemented, EMS has been associated with a reduction in morbidity and mortality related to emergency conditions. ${ }^{2,3}$

Pre-hospital emergency medical services should be given priority, especially in low- and middle-income countries (LMIC) where the prevalence of trauma and
Correspondence: Goitom Molalign

Takele

Department of Emergency and Critica Care Nursing, School of Nursing, College of Health Sciences, Mekelle University, P.O.box 187I, Mekelle, Ethiopia

Tel +251914697880

Email goitommolalign49@gmail.com 
trauma-associated mortalities are higher. ${ }^{4,5}$ Similarly, the peoples living in sub-Saharan Africa, including Ethiopians have been facing a disproportionate burden of acute illnesses and injuries. ${ }^{6-8}$ Additionally, the rapidly growing prevalence and complications of non-communicable diseases such as cardiovascular and diabetes in Ethiopia further necessitate the need for the establishment of an integrated EMS system. ${ }^{9}$

Although both the World Health Organization and the African Federation for Emergency Medicine have been promoting the formation of locally appropriate EMS system in low-income countries, ${ }^{10,11}$ the limited availability of resources, shortage of facilities and EMS technicians, financial constraints, and the infrastructure gaps still hinders the development and implementation of integrated EMS systems in these countries. ${ }^{11-14}$

The utilization of EMS in low-income countries ranges from $4 \%$ to $23 \% .^{15-18}$ In these countries, the utilization of EMS was found to be affected by financial problems, lack of awareness, perceived waiting time, misconceptions, use of traditional modes of transportation, prior experience with EMS, and absence of predefined and well-organized EMS. 16,17,19,20

In Ethiopia, the development of pre-hospital and inhospital emergency medical services has shown an improvement in terms of manpower, facilities, and involvement of private sectors. ${ }^{21}$ But, these improvements have been limited only to the capital Addis Ababa which have a single dispatch center of Addis Ababa Fire and Emergency Prevention and Control Authority (AAFEPCA) with a toll-free "939" call center, along with few private companies (Tebta and Estnfas ambulances) providing EMS throughout the city.

Mekelle the second populous city in the country, with the highest traffic flow and booming construction activities next to Addis Ababa, has no formal EMS dispatch center and pre-hospital emergency services are being delivered by ambulances from the government hospitals, Red Cross society, and some private hospitals. Studies exploring the utilization and barriers of EMS at the community level are scarce. A structured need assessment is an essential first step in health service development and is necessary to establish existing capacity and identify priorities for development. $^{22}$ Therefore, this study aimed to determine the utilization, identify the barriers and determinants of EMS in Mekelle city, Tigray, Ethiopia.

\section{Methods}

\section{Study Design and Setting}

A community-based cross-sectional study was conducted for 2 months from February to March 2020, in Mekelle, the capital city of the Tigray regional state. It is located $783 \mathrm{~km}$ north of Addis Ababa. Administratively it is a special zone, which is divided into seven sub-cities, namely: "Hawelti", "Adi Haki", "Kedamay-Weyane", "Hadnet", "Ayder", "Semien", and "Quiha". The city has one specialized referral hospital, three general hospitals, nine health centers, and several private clinics and hospitals. According to the most recent Ethiopian census of 2007 , the total population of the city was about 258,258. The city has an estimated number of more than 40 ambulances transporting patients from the scene to the hospitals, health centers, and private clinics. The emergency department of the largest hospital in the city (Ayder comprehensive specialized hospital) has an average of more than 130 emergency case visits daily.

\section{Study Participants}

The sample size was calculated using the single population proportion formula, assuming a 95\% confidence interval, $5 \%$ margin of error (d), taking the proportion of EMS utilization in Addis Ababa 20.1\%, ${ }^{17}$ using a design effect of 2 , and adding a non-response rate of $10 \%$ yielded a total sample size of 550. A total of 550 participants who were greater than 18 years old and agreed to participate were included, while those with any form of memory (psychiatric) problems were excluded from the study.

\section{Data Collection Tool}

A modified standard survey instrument was adopted from the study conducted in Ghana. ${ }^{16}$ The English version of the questionnaire was translated first into the local language Tigrinya and then back into English. The tool had 42 items categorized as demographic data, previous experience with EMS, knowledge, perception of EMS (availability, accessibility, accommodation, affordability, and acceptability), perception of ambulance performance, and hypothetical scenarios.

\section{Data Collection Procedure}

To conduct a balanced community-based study, four subcities (Kedamay weyane, Hawelti, Quiha, and Hadnet) were selected considering the residential nature, 
socioeconomic, geographic, and traffic flow of the subcities. From each sub-city, five kebelles were randomly selected. To attain as broad a sample as possible, diverse areas including the roadside, commercial areas, residential areas, schools, places of worship, and recreational areas were used as recruitment sites. Study participants were recruited using a systematic random sampling every sixth to eighth household from each recruitment kebelle's with a goal of 27 interviews per kebelle. An approximately equal number of people were interviewed within each enumeration area and the sample was allocated proportionally. One person from the household who met the inclusion criteria was selected and interviewed using a structured Tigrinya version questionnaire. Data were collected by eight health extension workers (two for each sub-city) who were trained for 2 days 1 week before the actual data collection time. Two supervisors have been leading the data collection and checking for completeness of the collected data daily. The questionnaire took $20-30$ minutes to complete.

\section{Data Analysis}

The data were cleaned, coded, entered into Epidata.3.1, and then exported into SPSS version 25 for analysis. Descriptive statistics including mean, median, range, and standard deviations for continuous data, as well as percentage and frequency tables for categorical data were computed.

In the survey, participants were presented with two hypothetical emergencies and asked how they would prefer to transport a victim to the hospital. In the first scenario, the participant witnessed a pedestrian on the street struck by a car, implying accessibility to many private and commercial vehicles. In the second scenario, a person with a fall-down accident being hurt badly in a house implying limited access to private or commercial vehicles. The primary outcome for regression analysis was the response to the question, "If you saw a pedestrian hit by a car and they needed to go to a hospital immediately, how would you get them to the hospital?" and the same for the second scenario also. Answers were then dichotomized into "ambulance" (combining the Red Cross ambulance, government hospitals, and other private ambulance options) and "non-ambulance" (private cars, Bajaj's, or three-wheel drive, motorcycle, and others) for analyzing using logistic regression. ${ }^{16}$ Bivariate and multivariate logistic regression analyses were employed to assess the effect of independent variables (demographic data, previous experience with EMS, knowledge, and perception of EMS (availability, accessibility, accommodation, affordability, and acceptability)) on the dependent variable (ambulance preference). Variables with $\mathrm{p}$-value $<0.25$ on bivariate logistic regression analysis were subjected to multiple logistic regression analysis. In multivariate logistic regression model fitness was tested using the Hosmer-Lemeshow goodness-of-fit. Adjusted odds ratio (AOR) with a $95 \%$ confidence interval was estimated to assess the strength of the association with ambulance preference. A p-value less than 0.05 was considered significant.

\section{Operational Definition}

- EMS utilization was defined as the use of an ambulance as a means of transporting and treatment of an ill or injured person from the scene to the hospital.

- Emergency condition: participant's judgment expressing that he or she had a condition severe enough to seek healthcare including immediate emergency care use.

- Kebelle: the smallest city administration next to a sub-city.

\section{Results}

Five hundred and fifty participants were approached and 546 had completed the interview, making a response rate of $96 \%$. Of these 546 participants from the four sub-cities, $215(39.4 \%)$ were from residential areas, 205 (37.6\%) from business areas, and the remaining from the street and others.

\section{Socio-Demographic Characteristics of the Respondents}

The mean (SD) age of the respondents was 35 (11.8) years, with $266(48.7 \%)$ of them being within the age range of $18-32$ years. Three hundred nine $(56.6 \%)$ of the respondents were males and nearly half $(49.5 \%)$ of them were married. Only $80(14.7 \%)$ participants had a private car and the vast majority $514(94.1 \%)$ of them had a cell phone. Two hundred thirty-one $(42.3 \%)$ of the participants had completed at least secondary education (Table 1).

\section{Previous Experience of EMS}

In the past year, $278(50.5 \%)$ of the respondents had experienced or witnessed an emergency incident, which are both medical 172 (62.3\%) and traumatic 106 (37.7\%) emergencies requiring urgent medical help. One-third (34.5\%) of these emergency cases were experienced by the participants 
Table I Socio-Demographic Characteristics of the Respondents $(n=546)$

\begin{tabular}{|c|c|c|}
\hline Variables & Category & $\mathbf{N}(\%)$ \\
\hline \multirow[t]{2}{*}{ Sex } & Female & $237(43.3)$ \\
\hline & Male & $309(56.6)$ \\
\hline \multirow[t]{4}{*}{ Age (years) } & $18-32$ & $266(48.7)$ \\
\hline & $33-47$ & $193(35.3)$ \\
\hline & $48-62$ & $65(12)$ \\
\hline & $>63$ & $22(4)$ \\
\hline \multirow[t]{4}{*}{ Marital status } & Single & $210(38.5)$ \\
\hline & Married & $270(49.5)$ \\
\hline & Divorced & $4 \mid(7.5)$ \\
\hline & Widowed & $25(4.5)$ \\
\hline \multirow[t]{3}{*}{ Religion } & Orthodox & $405(74.2)$ \\
\hline & Muslim & $118(21.6)$ \\
\hline & Others* & $23(4.2)$ \\
\hline \multirow[t]{6}{*}{ Occupation } & Employed & $37 \mid(67.9)$ \\
\hline & Unemployed & $61(11.2)$ \\
\hline & House wife & $35(6.4)$ \\
\hline & Farmer & $15(2.7)$ \\
\hline & Student & $52(9.5)$ \\
\hline & Other** & $12(2.2)$ \\
\hline \multirow[t]{4}{*}{ Educational status } & Illiterate & $31(5.7)$ \\
\hline & Primary school & I0I (18.5) \\
\hline & Secondary school & $231(42.5)$ \\
\hline & College and above & $183(33.5)$ \\
\hline \multirow[t]{4}{*}{ Monthly income (ETB) } & $<500$ birr & $107(19.6)$ \\
\hline & $501-1000$ birr & $22(4)$ \\
\hline & $100 \mathrm{I}-2000 \mathrm{birr}$ & $59(10.8)$ \\
\hline & $>2001$ birr & $358(65.6)$ \\
\hline \multirow[t]{4}{*}{ Residence (sub-city) } & Quiha & I 35 (24.7) \\
\hline & Kedamay weyane & $138(25.3)$ \\
\hline & Hawelti & $137(25.1)$ \\
\hline & Hadnet & $136(24.9)$ \\
\hline \multirow[t]{2}{*}{ Having mobile phone } & Yes & $514(94.1)$ \\
\hline & No & $32(5.9)$ \\
\hline
\end{tabular}

(Continued)
Table I (Continued).

\begin{tabular}{|l|l|l|}
\hline Variables & Category & N (\%) \\
\hline Having car & Yes & $80(14.7)$ \\
\cline { 2 - 3 } & No & $466(85.3)$ \\
\hline Health insurance & Yes & $91(16.7)$ \\
\cline { 2 - 3 } & No & $455(83.3)$ \\
\hline
\end{tabular}

Notes: *Protestant, catholic, and Seventh-day Adventist, **Retired, daily laborer. Abbreviation: ETB, Ethiopian Birr.

themselves. The commonly used means of transportation used to take victims to a hospital were Bajaj (three-wheel drive motor) $39.2 \%$, ambulance $22.7 \%$, taxi, and private car $16.9 \%$, and respectively. One hundred and fifteen (40\%) of the emergency incidents happened at home. Of the 58 participants who used ambulance services, 22 (37.9\%) were pregnant mothers in labor (Table 2).

\section{Knowledge and Perceptions of Ambulance Services}

A significantly higher number of respondents 453 (83\%) believed that the number of ambulances in Mekelle city is not enough. Only $42(7.7 \%)$ had ever made a call for an ambulance service. One hundred fifty (27.5\%) of the respondents were able to recall ambulance numbers, ie, 65 (11.9\%) and $85(15.6 \%)$ their nearby government ambulance and Red Cross ambulance phone numbers, respectively.

The majority ( $83 \%$ ) of the respondents were confident of getting ambulance services after making a phone call. Three hundred forty-five (63.2\%) and $176(32.2 \%)$ of the respondents reported that they expected an ambulance to arrive within 16-60 minutes during peak traffic hours and within less than 15 minutes during non-peak traffic hours after call respectively.

The vast majority of the respondents knew that the government and Red Cross ambulances are providing services for free 507 (92.9\%) and 525 (96.2\%) respectively. Concerning the intention of calling for ambulance services, $482(88.3 \%)$ of the respondent reported that they would be more likely to make a call if it was a toll-free and a three-digit number.

Regarding the perception of ambulance services, 280 $(51.3 \%)$ of the respondents believed that ambulance technicians (emergency medical technicians) offer high-quality care. More than half $(51.5 \%)$ of the respondents reported 
Table 2 Previous Emergency Medical Services Experience of the Respondents $(n=546)$

\begin{tabular}{|c|c|c|}
\hline Variables & Category & $\mathbf{N}(\%)$ \\
\hline \multirow[t]{2}{*}{ Previous experience of EMS } & Yes & $181(33.2)$ \\
\hline & No & $365(66.8)$ \\
\hline \multirow{2}{*}{$\begin{array}{l}\text { Witnessed emergency incident } \\
\text { in the past I year }\end{array}$} & Yes & $276(50.5)$ \\
\hline & No & $270(49.5)$ \\
\hline \multirow{3}{*}{$\begin{array}{l}\text { Victim of the emergency } \\
\text { incidence }\end{array}$} & Self & $96(34.5)$ \\
\hline & $\begin{array}{l}\text { Family } \\
\text { member }\end{array}$ & III (39.9) \\
\hline & Others & $71(25.6)$ \\
\hline \multirow[t]{4}{*}{ Emergency scene } & Home & $115(40.2)$ \\
\hline & Work & $82(28.7)$ \\
\hline & $\begin{array}{l}\text { School and } \\
\text { playground }\end{array}$ & $47(16.4)$ \\
\hline & Street & $42(14.7)$ \\
\hline \multirow[t]{2}{*}{ Type of emergency } & Medical & $170(61.9)$ \\
\hline & Trauma & $106(38.1)$ \\
\hline \multirow[t]{9}{*}{ Emergency case } & Neurological & $35(12.6)$ \\
\hline & Cardiovascular & $36(12.9)$ \\
\hline & $\begin{array}{l}\text { Trauma/ } \\
\text { hemorrhage }\end{array}$ & $58(20.9)$ \\
\hline & Psychiatric & $21(7.6)$ \\
\hline & Pediatrics & $28(10.1)$ \\
\hline & $\begin{array}{l}\text { Labor/ } \\
\text { obstetric }\end{array}$ & $35(12.6)$ \\
\hline & Ophthalmic & $14(5)$ \\
\hline & Infection & $39(14)$ \\
\hline & Others* & $12(4.3)$ \\
\hline \multirow{3}{*}{$\begin{array}{l}\text { Severity of the emergency } \\
\text { incident }\end{array}$} & Mild & $45(16.2)$ \\
\hline & Moderate & $169(60.8)$ \\
\hline & Severe & $64(23)$ \\
\hline \multirow[t]{2}{*}{ Did you go to the hospital? } & Yes & $254(91.4)$ \\
\hline & No & $24(8.6)$ \\
\hline
\end{tabular}

Table 2 (Continued).

\begin{tabular}{|l|l|l|}
\hline Variables & Category & N (\%) \\
\hline $\begin{array}{l}\text { Accompanied to go to the } \\
\text { hospital }\end{array}$ & Alone & $76(27.3)$ \\
\cline { 2 - 3 } & Police & $24(8.6)$ \\
\cline { 2 - 3 } & Bystander & $9(3.2)$ \\
\cline { 2 - 3 } hospital & Family & $145(52.2)$ \\
\cline { 2 - 3 } & Driver & $24(8.6)$ \\
\hline \multirow{5}{*}{$\begin{array}{l}\text { Type of transport used to go to } \\
\text { Ambulance }\end{array}$} & $58(22.7)$ \\
\cline { 2 - 3 } & Taxi & $43(16.9)$ \\
\cline { 2 - 3 } & Private car & $43(16.9)$ \\
\cline { 2 - 3 } & Bajaj & $100(39.2)$ \\
\cline { 2 - 3 } & On foot & $5(2)$ \\
\cline { 2 - 3 } & $\begin{array}{l}\text { Do not } \\
\text { remember }\end{array}$ & $8(2.4)$ \\
\hline \multirow{5}{*}{. } & & \\
\hline
\end{tabular}

Notes: *Allergic reaction, poisoning, burn.

that ambulances are being used for the transport of critically ill patients (Table 3 ).

\section{Determinants of Ambulance Services Utilization}

On multivariate logistic regression analysis to identify determinants of ambulance services utilization among the ambulance used groups, we found that those who had gynecologic emergencies (labor case) were 9.4 times (AOR=9.4, 95\% CI: 1.04,85, $\mathrm{p}=0.046$ ), and those who knew any ambulance number were 3.6 times $(\mathrm{AOR}=3.6$, $95 \%$ CI: $1.22,10.8, \mathrm{p}=0.02)$ more likely to use ambulance services in case of emergency conditions.

\section{Hypothetical Scenario}

In response to both hypothetical questions, ie, witnessing a pedestrian severely struck by a vehicle and a person with a fall-down accident being hurt badly in a house, 177 $(42.2 \%)$ of the respondents answered they would call ambulance followed by Bajaj $(141,33.7 \%)$ and taxi (48, $11.5 \%$ ) for transporting the victim to the hospital. There was no much difference in the preference of a mode of 
Table 3 Knowledge and Perception of Emergency Medical Service Use, in Mekelle $(n=546)$

\begin{tabular}{|c|c|c|c|}
\hline Variable & & Category & $\mathbf{N}(\%)$ \\
\hline \multirow[t]{10}{*}{ Availability } & $\begin{array}{l}\text { Perception of enough } \\
\text { ambulance }\end{array}$ & Yes & $93(17)$ \\
\hline & & No & $453(83)$ \\
\hline & $\begin{array}{l}\text { Ever made ambulance } \\
\text { call }\end{array}$ & Yes & $42(7.7)$ \\
\hline & & No & $504(92.3)$ \\
\hline & $\begin{array}{l}\text { Ever used ambulance } \\
\text { service before }\end{array}$ & Yes & $50(9.2)$ \\
\hline & & No & $496(90.8)$ \\
\hline & $\begin{array}{l}\text { Can name RCA } \\
\text { number }\end{array}$ & Yes & $85(15.6)$ \\
\hline & & No & $46 \mid(84.4)$ \\
\hline & $\begin{array}{l}\text { Can name nearby } \\
\text { ambulance number }\end{array}$ & Yes & 65 (11.9) \\
\hline & & No & 481 (88.I) \\
\hline \multirow[t]{10}{*}{ Accessibility } & $\begin{array}{l}\text { Expected ambulance } \\
\text { response } \\
\text { time during peak } \\
\text { traffic hours }\end{array}$ & $\leq 15$ minutes & $45(8.2)$ \\
\hline & & $\begin{array}{l}16-59 \\
\text { minutes }\end{array}$ & $345(63.2)$ \\
\hline & & $\geq 60$ minutes & $156(28.6)$ \\
\hline & $\begin{array}{l}\text { Expected ambulance } \\
\text { response } \\
\text { time during non-peak } \\
\text { traffic hours }\end{array}$ & $\leq 15$ minutes & $176(32.2)$ \\
\hline & & $\begin{array}{l}16-59 \\
\text { minutes }\end{array}$ & $305(55.9)$ \\
\hline & & $\geq 60$ minutes & 65 (11.9) \\
\hline & $\begin{array}{l}\text { Know any ambulance } \\
\text { number }\end{array}$ & Yes & $286(52.4)$ \\
\hline & & No & $260(47.6)$ \\
\hline & $\begin{array}{l}\text { Perception of getting } \\
\text { ambulance on call }\end{array}$ & Yes & $453(83)$ \\
\hline & & No & $93(17)$ \\
\hline \multirow[t]{4}{*}{ Affordability } & $\begin{array}{l}\text { Knowledge of free } \\
\text { gov't ambulance }\end{array}$ & Yes & $507(92.9)$ \\
\hline & & No & $39(7.1)$ \\
\hline & $\begin{array}{l}\text { Knowledge of free } \\
\text { RCA }\end{array}$ & Yes & $525(96.2)$ \\
\hline & & No & $21(3.8)$ \\
\hline
\end{tabular}

(Continued)
Table 3 (Continued).

\begin{tabular}{|c|c|c|c|}
\hline Variable & & Category & $\mathbf{N}(\%)$ \\
\hline & $\begin{array}{l}\text { Intention to call } \\
\text { ambulance if it was } \\
\text { toll free }\end{array}$ & Yes & $482(88.3)$ \\
\hline & & No & 64 (II.7) \\
\hline \multirow[t]{8}{*}{ Acceptability } & $\begin{array}{l}\text { Perception of high } \\
\text { quality care by } \\
\text { ambulance technician }\end{array}$ & Yes & $280(51.3)$ \\
\hline & & No & $266(48.7)$ \\
\hline & $\begin{array}{l}\text { Perception that } \\
\text { ambulance is safer } \\
\text { than taxi }\end{array}$ & Yes & $516(94.5)$ \\
\hline & & No & $30(5.5)$ \\
\hline & $\begin{array}{l}\text { Perception that taxi } \\
\text { is faster than } \\
\text { ambulance }\end{array}$ & Yes & 71 (13) \\
\hline & & No & $475(87)$ \\
\hline & $\begin{array}{l}\text { Perception that } \\
\text { ambulance is better } \\
\text { than taxi }\end{array}$ & Yes & $503(92.1)$ \\
\hline & & No & $43(7.9)$ \\
\hline \multirow[t]{3}{*}{ Accommodation } & $\begin{array}{l}\text { Perception that an } \\
\text { ambulance is } \\
\text { important for patient } \\
\text { condition }\end{array}$ & Yes & $524(96)$ \\
\hline & & No & $22(4)$ \\
\hline & \multicolumn{2}{|c|}{$\begin{array}{l}\text { Importance of ambulance services } \\
\text { Transporting of ill person } \\
\text { Transporting of trauma victims } \\
\text { Inter facility patient transport } \\
\text { Transporting corpse }\end{array}$} & $\begin{array}{l}281(51.5) \\
196(35.9) \\
51(10.2) \\
13(2.4)\end{array}$ \\
\hline
\end{tabular}

transportation for victims among the scenes of the incident (street versus home).

A multivariate logistic regression analysis using a backward test was also run to assess the likelihood of calling an ambulance during emergencies in both scenarios. In the reported responses to call an ambulance if they witnessed a pedestrian-auto collision or fall-down accident in a house we found that respondent who had private car were 2 times more likely to call an ambulance $(\mathrm{AOR}=2$, $95 \% \mathrm{CI}: 1.1-3.8, \mathrm{p}=0.023$ ) as a means of transporting the victim. Reported Knowledge of free government ambulance services $\quad(\mathrm{AOR}=2.8,95 \% \mathrm{CI}: 1.2-6.2, \mathrm{p}=0.011)$ was also another predictor of the likely hood of calling 
an ambulance to the hypothesized scenario. Those who knew the Red Cross ambulance phone number were 2.6 times more likely to call for ambulance services in case of emergency $\quad(\mathrm{AOR}=2.6,95 \%$ CI: 1.3-5.1, $\mathrm{p}=0.006)$. Respondents who reported they would intend to call for ambulance service if it was a toll-free three-digit number were 2.6 times more likely to call for an ambulance ( $\mathrm{AOR}=2.6,95 \%$ CI: $1.4-4.7, \mathrm{p}=0.002)$ in case of emergency. There was also a significant association with a perceived ambulance waiting time and intention to call. Participants who reported that the acceptable ambulance arrival time to the scene after call should be less than 15 minutes and between 16 and 60 minutes were found 2.1 $(\mathrm{AOR}=2.1,95 \% \mathrm{CI}: 1.0-4.2, \mathrm{p}=0.033)$ and $2.8(\mathrm{AOR}=2.8$, 95\% CI: $1.5-5.3, \mathrm{p}=0.001)$ time more likely to call an ambulance compared to those who believed more than 1 hour in case of emergency conditions [Table 4].

To understand the participants' response on "what are ambulances currently being used for in Mekelle city" was provided and selected responses to this open-ended question are listed in Table 5 .

\section{Discussion}

As the proper functioning of integrated EMS in developing countries like Ethiopia is important to avert and decrease morbidity and mortality with time-sensitive illnesses and injuries, ${ }^{3}$ the objective of this study was to determine the utilization and identify barriers and determinants of EMS in Mekelle city.

In this study half $(50.5 \%)$ of the respondents had experienced or witnessed a medical or traumatic emergency within the past year. Ambulances were used for transporting $58(22.7 \%)$ of the victims from the scene into the hospital. This is consistent with studies conducted in Lebanon $23 \%{ }^{15}$ and Addis Ababa, Ethiopia $20 \% .{ }^{17}$ But, higher as compared to studies conducted in Ghana which showed that the ambulance utilization rate by the general population ranges from $5 \%$ to $14.7 \% .^{16,18}$

The high rate of utilization might be attributed to the notion that most of the cases (38\%) transported by ambulance in our study were labor cases in which the community (especially pregnant women's) was well informed regarding access to ambulance services during their antenatal follow up to decreasing maternal mortality and promotion of inhospital delivery for safe delivery and healthy baby outcome by the government. As expected, labor cases were 9.4 times ( $\mathrm{AOR}=9.4,95 \% \mathrm{CI}: 1.04,85, \mathrm{p}=0.046)$ more likely to use ambulance services. Similarly, studies conducted in Addis Ababa, Ethiopia, and Uganda found that ambulance services were used mostly for obstetric (labor) cases. ${ }^{23,24}$

Table 4 The Likelihood of Calling an Ambulance in Hypothetical Pedestrian-Auto Collision and a Person with Fall-Down Accident Being Hurt Badly in a House $(n=546)$

\begin{tabular}{|c|c|c|c|c|c|c|}
\hline \multirow[t]{2}{*}{ Variables } & \multirow[t]{2}{*}{ Response } & \multicolumn{2}{|c|}{ Calling an Ambulance } & \multirow[t]{2}{*}{ COR $(95 \% \mathrm{Cl})$} & \multirow{2}{*}{$\begin{array}{l}\text { AOR } \\
(95 \% \mathrm{CI})\end{array}$} & \multirow[t]{2}{*}{ p-value } \\
\hline & & No & Yes & & & \\
\hline \multirow[t]{2}{*}{ Having car } & Yes & $18(8.3)$ & $62(18.9)$ & $2.5(1.4,4.5)$ & $2\left(\begin{array}{lll}1 & 0.1,3.8\end{array}\right)$ & 0.023 \\
\hline & No & $200(91.7)$ & $266(8 I .1)$ & I & I & \\
\hline \multirow[t]{2}{*}{ Know free of charge gov't ambulance service } & Yes & $191(87.6)$ & $316(96.3)$ & $3.7(1.8,7.5)$ & $2.8(1.2,6.2)$ & 0.011 \\
\hline & No & $27(12.4)$ & $12(3.7)$ & I & 1 & \\
\hline \multirow[t]{2}{*}{ Able to recall RCA number } & Yes & $21(9.6)$ & $64(19.5)$ & $2.2(1.3,3.8)$ & $2.6(1.3,5.1)$ & 0.006 \\
\hline & No & 197(90.4) & $264(80.5)$ & I & I & \\
\hline \multirow[t]{2}{*}{ Intention to call if it was toll-free three-digit number } & Yes & $175(80)$ & $307(93.6)$ & $3.5(2.0,6.2)$ & $2.6(1.4,4.7)$ & 0.002 \\
\hline & No & $43^{20}$ & $21(6.4)$ & I & I & \\
\hline \multirow[t]{3}{*}{ Perceived ambulance waiting time } & $<15 \min$ & $68(31.2)$ & $108(32.9)$ & $2.9(1.6,5.2)$ & $2.1(1.0,4.2)$ & 0.033 \\
\hline & $16-60 \mathrm{~min}$ & $108(49.5)$ & $197(60.1)$ & $3.3(1.9,5.8)$ & $2.8(1.5,5.3)$ & 0.001 \\
\hline & $>60$ min & $42(19.3)$ & $23^{7}$ & I & I & \\
\hline
\end{tabular}

Abbreviations: COR, crude odds ratio; AOR, adjusted odds ratio; RCA, Red Cross ambulance; gov't, government; Hosmer-Lemeshow goodness-of-fit=0.457. 
Table 5 Selected Responses About Current Use of Ambulance in Mekelle Based on Their Appropriateness

\begin{tabular}{|c|c|}
\hline Appropriate Use of Ambulance & In Appropriate Use of Ambulance \\
\hline $\begin{array}{l}\text { *"it is better to use ambulance than taxi for transporting pregnant women's } \\
\text { who are in labor to the hospital, because they can deliver safely in the } \\
\text { ambulance with the help of ambulance technicians." } \\
\text { *"for transporting sick child to the hospital's" } \\
\text { *"for transporting victims of any types of emergency conditions who need } \\
\text { immediate care like in case of car accidents and burn" } \\
\text { *"ambulances are faster and safer to use than other vehicles for transporting } \\
\text { a person in need of urgent medical care" }\end{array}$ & $\begin{array}{l}\text { *"they are giving transport services for government officials" } \\
\text { *"they are being used for the government security services" } \\
\text { *"it is better to use ambulance than other vehicles when } \\
\text { transporting a dead body" } \\
\text { *"sometimes ambulances are being used for transporting a non- } \\
\text { injured or diseased patient for financial gains of the drivers" }\end{array}$ \\
\hline
\end{tabular}

In response to the hypothetical scenarios (pedestrian hit by a car and a person with fall-down accident being hurt badly in a house) majority (46.2\%) prefer ambulance as their preferred transport option in both scenarios, followed by $16 \%$ of Bajaj's. This finding is higher compared to a study conducted in Ghana where the majority of the respondents reported they would prefer a taxi. ${ }^{16,18}$ This could be due to the majority of our respondents were confident of getting ambulance services after the call and their perceived belief in getting high-quality care by ambulance emergency medical technicians.

Even though a majority of the respondents were aware of the free of charge services were being provided by the government ambulances (93\%) and Red Cross ambulances (96.2\%), a considerable number of them did not know government ambulances (88.1\%), as well as Red Cross (84.4\%) ambulance access call numbers. This is in disagreement with studies conducted in Addis Ababa, Ethiopia, ${ }^{17}$ and Accra, Ghana, ${ }^{16}$ where the general public had a good knowledge of ambulance access numbers. This could be due to the involvement of private ambulance services, which might have an impact on creating awareness to the public through their advertisement and the presence of toll-free threedigit call access for emergency services in these cities might make it easy to access and remember. Furthermore, this is also supported by our finding, where respondents reported that they would be more likely to call for an ambulance if it was a toll-free call service $(\mathrm{AOR}=2.6,95 \% \mathrm{CI}, 1.4,4.7, \mathrm{p}=0.002)$. This paucity and misconception of access to phone calls for ambulance services are indicatives of the need for awareness creation and promotion of access to ambulance services for the general public.
This study found that the majority of the respondents had a good perception of ambulance services: where 93\% of them were confident of getting ambulance services after a call, 97\% knew at least one appropriate indication for ambulance service, and more than half perceived that ambulance technicians would provide high-quality care, and majorities also perceived that ambulances are safer, faster, and better than a taxi. In line with other studies, the vast majority of the participants also perceived that there were not enough ambulances in the city. ${ }^{16,17}$

On multiple logistic regression analysis of the hypothetical questions, we found that those who knew RCA number, those who knew government ambulance services are free of charge, those who believed that they would intend to call an ambulance if it was toll-free, and perceived ambulance waiting time of less than an hour were more likely to call an ambulance in case of any emergencies. This shows that there is a huge gap regarding knowing ambulance access numbers and misconceptions of the services, which suggests a community-wide awareness creation that can be done by publicly notifying through mass media.

Different studies from Gabon, ${ }^{19}$ Ethiopia, ${ }^{17}$ Ghana, ${ }^{16}$ and Lebanon ${ }^{15}$ have identified that lack of awareness, misperceptions, established alternatives, perceived ambulance waiting time, language barrier, previous EMS use, perceived severity of illness, perceived benefits of EMS, and cost as barriers of EMS service utilization. Similarly, our study found that established alternatives, lack of awareness of EMS access, lack of toll-free three-digit designated emergency call services, and lack of integrated EMS are the barriers to access and utilization of EMS in our city. 
The establishment of integrated EMS services in Mekelle is warranted as our findings support that majority of the services provided are fragmented and mainly used for transporting a sick child or mothers in labor to the hospital. As experience from Addis Ababa, Ethiopia showed that the integrated single centered dispatch center in each sub-city is providing a well-organized EMS services to the city, and harmonizing the available ambulances of our city could replicate the success of integrating the system from Addis Ababa. Additionally, training bystanders about cardiopulmonary resuscitation and first aid care would also enhance the awareness of the community towards the EMS.

\section{Conclusion}

In conclusion, the ambulance utilization level in Mekelle city was low and victims of emergency conditions were being transported mainly by Bajaj's and taxis. Even though the general public perception towards EMS services was favorable, lack of awareness of EMS access and lack of integrated EMS system in the city were the barriers that may have contributed to the low utilization. Gynecologic (labor) emergencies and knowing any ambulance phone number were the determinants of EMS utilization. Actions to improve EMS access and integrating the system are warranted to promote the utilization of the services.

\section{Strengths and Limitations}

This study was the first one to assess the ambulance service utilization, identify the barriers, and determinants at a community level. As a limitation, even though, emergency incidents are less likely to be forgotten recall biases are still the shortcoming of this study. The decisions made to the hypothetical questions may not infer to the actual decision that would be made by the respondents at the time of emergency incidents. Additionally, the literary translation of the survey questions from English, to Tigrinya, back to English might not be enough to validate the tool.

\section{Abbreviations}

AOR, adjusted odds ratio; $\mathrm{CI}$, confidence interval; COR, crude odds ratio; EMS, Emergency Medical Services; LMIC, low- and middle-income countries; RCA, Red Cross ambulance; SD, standard deviation; SPSS, Statistical Package for Social Sciences.

\section{Data Sharing Statement}

Data supporting the findings in this paper are available upon reasonable request from the corresponding author and the summary data are available on the main document.

\section{Ethical Approval}

This study was conducted by following the Declaration of Helsinki, and approval was obtained from Mekelle University, College of Health Sciences, Ethical review board (ERC 1506/2020). The informed written consent form was obtained from the participants before proceeding with the data collection. Participant's autonomy was maintained by telling them that they can refuse or stop participation at any time. Confidentiality was maintained by not including their names or other identifiers in the data collection tool.

\section{Consent for Publication}

Not applicable

\section{Acknowledgments}

The authors would like to thank the study participants, health managers of the sub-cities and the Tigray Regional Health Bureau, for their cooperation throughout the data collection.

\section{Funding}

The study was supported by Mekelle University, College of Health Sciences. The funding does not have a further role in the design, data collection, analysis, drafting, manuscript preparation, and publication of this paper.

\section{Disclosure}

The authors declare that they have no competing interests.

\section{References}

1. Kobusingye OC, Hyder AA, Bishai D, et al. Emergency Medical Services. Jamison DT, Breman JG, Measham AReditors. Disease Control Priorities in Developing Countries. 2nd ed. Washington DC: The International Bank for Reconstruction and Development/the World Bank;2006.

2. Mahama M, Kenu E, Bandoh DA, Zakariah AN. Emergency response time and pre-hospital trauma survival rate of the national ambulance service, Greater Accra. BMC Emerg Med. 2018;18(33):3-9.

3. Sasser S, Varghese M, Kellermann A, Lormand JD. Prehospital Trauma Care Systems. Geneva: World Health Organization; 2005.

4. Mathers C, Fat DM, Boerma JT, World Health OrganizationThe global burden of disease: 2004 update. Geneva: World Health Organization. 2008;146 p

5. Gosselin RA. The Increasing Burden of Injuries in Developing Countries, Techniques in Orthopaedics. 2009;24(4):230-232. 
6. Ugare GU, Bassey IE, Udosen JE, et al. Trauma death in a resource constrained setting: mechanisms and contributory factors, the result of analysing 147 cases. Niger J Clin Pract. 2014;17(4):397-402. doi:10.4103/1119-3077.133965.

7. IGO. G Status Report on Road Safety 2018: Summary. GWHO 2018 (WHO/NMH/NVI/18. 20). LCB-N-S 3. Global Status Report on Road Safety 2018: Summary. Geneva: World Health Organization; 2018.

8. Sawe HR, Mfinanga JA, Mbaya KR, et al. Trauma burden in Tanzania: a one-day survey of all district and regional public hospitals. BMC Emerg Med. 2017;17(1):30.

9. Mathers CD, Loncar D. Projections of global mortality and burden of disease from 2002 to 2030. PLoS Med. 2006;3(11):e442. doi:10.1371/journal.pmed.0030442

10. Mould-Millman NK, Naidoo R, De Vries S, Stein C, Wallis LA, AFEM consensus conference. AFEM out-of-hospital emergency care workgroup consensus paper: advancing out-of-hospital emergency care in Africa-advocacy and development. African J Emerg Med. 2014;4(2):90-95. doi:10.1016/j.afjem.2014.02.001

11. Razzak JA, Kellermann AL. Emergency medical care in developing countries: is it worthwhile? Bull World Heal Organ. 2002;80:01.

12. Frimpong J, Prof RD. Ambulance emergency services and healthcare provision in Ghana: a district level performance appraisal. 2014;3 (1):13-23.

13. Hsia RY, Mbembati NA, Macfarlane S, Kruk ME. Access to emergency and surgical care in sub-Saharan Africa: the infrastructure gap. Health Policy Plan. 2012;27(March 2011):234-244.

14. Germa F, Bayleyegn T, Kebede T, Ducharme J. Emergency medicine development in Ethiopia: challenges, progress and possibilities ' veloppement de la me ' decine d' urgence en Ethiopie: de ' fis, De ' $s$ et possibilities progre. African J Emerg Med. 2014;3(1):3-9. doi:10.1016/j.afjem.2012.08.005

15. El Sayed M, Tamim H, Chehadeh AA, Kazzi AA. Emergency medical services utilization in EMS priority conditions in Beirut, Lebanon. Prehosp Disaster Med. 201631(6):621-627. doi:10.1017/ S1049023X16000972

16. Mould-Millman NK, Rominski SD, Bogus J, et al. Barriers to accessing emergency medical services in Accra, Ghana: development of a survey instrument and initial application in Ghana. Glob Heal Sci Pract. 2015;3(4):577-590.
17. Sultan M, Abebe Y, Tsadik AW, et al. Trends and barriers of emergency medical service use in Addis Ababa; Ethiopia. BMC Emerg Med. 2019;19(28). doi:10.1186/s12873-019-0242-5

18. Mould-millman CN, Rominski S. African Federation for Emergency Medicine African Journal of Emergency Medicine Ambulance or taxi? High acuity prehospital transports in the Ashanti region of Ghana Ambulance ou Taxi? Le transport pre' hospitalier des patients gravement malades dans la. African J Emerg Med. 2014;4 (1):8-13. doi:10.1016/j.afjem.2013.04.004

19. Bosson N, Redlener MA, Foltin GL, Raven MC, Foran MP, Wall SP. Barriers to utilization of pre-hospital emergency medical services among residents in Libreville, Gabon: a qualitative study ' 1' utilisation des services d' urgence me ' dicale Obstacles a' hospitaliers parmi les habitants de Libreville, Gabon: pr. African J Emerg Med. 2013;3(4):172-177. doi:10.1016/j.afjem.2012.12.003

20. Balikuddembe JK, Ardalan A, Khorasani-Zavareh D, Nejati A, Raza O. Weaknesses and capacities affecting the Prehospital emergency care for victims of road traffic incidents in the greater Kampala metropolitan area: a cross-sectional study. BMC Emerg Med. 2017;17 (1):29.

21. Germa F, Bayleyegn T, Kebede T, et al. Emergency medicine development in Ethiopia: challenges, progress and possibilities. Afr J Emerg Med. 2013;3(1):3-9.

22. VanRooyen MJ. Development of prehospital emergency medical services: strategies for system assessment and planning. Pac Health Dialog. 2002;9(1):86-92.

23. De Ramirez SS, Doll J, Carle S, et al. Emergency response in resource-poor settings: a review of a newly-implemented EMS system in rural Uganda. Prehosp Disaster Med. 2014;29(3):311-316.

24. Sultan M, Abebe Y, Tsadik AW, Jennings CA, Mould-Millman NK. Epidemiology of ambulance utilized patients in Addis Ababa, Ethiopia. BMC Health Serv Res. 2018;18(1):1-7.
Open Access Emergency Medicine

\section{Publish your work in this journal}

The Open Access Emergency Medicine is an international, peerreviewed, open access journal publishing original research, reports, editorials, reviews and commentaries on all aspects of emergency medicine. The manuscript management system is completely online and includes a very quick and fair peer-review system, which is all easy to use. Visit http://www.dovepress.com/testimonials.php to read real quotes from published authors. 